\title{
EFEITOS DA QUITOSANA NO DESENVOLVIMENTO in vitro DE VIDEIRAS cv. MERLOT E NO CRESCIMENTO MICELIAL DO FUNGO Elsinoe ampelina
}

\author{
Effects of the chitosan on the development of grapevines cv. Merlot and on the \\ mycelial growth of the fungus Elsinoe ampelina
}

\author{
Aline José Maia ${ }^{1}$, Carla Daiane Leite ${ }^{2}$, Renato Vasconcelos Botelho ${ }^{3}$, \\ Cacilda Márcia Duarte Rios Faria², Suelen Cristina Uber²
}

\begin{abstract}
RESUMO
Objetivou-se, neste trabalho, avaliar o efeito da quitosana no desenvolvimento in vitro de plântulas de videira cv. Merlot e sua atividade antifúngica sobre Elsinoe ampelina. No primeiro experimento, explantes da cultivar Merlot foram transferidos para meio de cultura DSD1, acrescido das concentrações 0; 25; 50,100; 150 e $200 \mathrm{mg} \mathrm{L}^{-1}$ de quitosana. Após 90 dias de cultivo in vitro, as plântulas foram avaliadas quanto ao número de raízes e de folhas, porcentagem de enraizamento e brotação, comprimento de raízes e de parte aérea, massa fresca da planta. No segundo experimento, incorporou-se às concentrações $0,60,120,180,240$ e $300 \mathrm{mg} \mathrm{L}^{-1}$ de quitosana ao meio BDA, onde inoculou-se o fungo. Posteriormente, avaliou-se o crescimento micelial aos 6 e 9 dias de incubação a $25^{\circ} \mathrm{C}$ no escuro. No primeiro experimento para as variáveis comprimento médio da parte aérea, massa fresca da planta inteira, porcentagem de enraizamento e porcentagem de estacas brotadas houve decréscimo linear em função das concentrações de quitosana. No segundo experimento, houve efeito linear negativo em função das concentrações crescentes de quitosana, sendo que a inibição do crescimento micelial foi de $81,7 \%$, demonstrando o grande potencial do uso de quitosana no controle da antracnose da videira.
\end{abstract}

Termos para indexação: Uva, Vitis vinifera L., antracnose da videira, agroecologia, fitopatologia.

\section{ABSTRACT}

The objective of this research was to evaluate the effects of the chitosan on the development in vitro plantlets of grapevines $\mathrm{cv}$. Merlot and its antifungal action on Elsinoe ampelina. In the first trial, explants of the grapevine cv. Merlot were transferred to growing medium DSD1 plus concentrations of $0 ; 25 ; 50 ; 100 ; 150$ and $200 \mathrm{mg} \mathrm{L}^{-1}$ of the product. After 90 days of in vitro cultivation the plantlets were evaluated for root and leaf number, root and shoot length and fresh mass of roots and shoots. In the second experiment, doses of $0 ; 60 ; 120 ; 180 ; 240$ and $300 \mathrm{mg} \mathrm{L}^{-1}$ were incorporated to the BDA media, where the fungus was inoculated. The mycelial diameter was evaluated at 6 and 9 days after incubation at $25^{\circ} \mathrm{C}$ in the dark. In the first experiment, for the variables shoot length average, plant fresh mass, rooting percentage and sprouted cuttings there was a linear reduction in function of chitosan doses. In the second trial, there was a negative linear effect with mycelial growth inhibition, of $81.7 \%$, showing great the potential of chitosan in the control of grapevine anthracnose.

Index terms: Grape, Vitis vinifera L., grapevine anthracnose, agroecology, phytopathology.

(Recebido em 17 de junho de 2009 e aprovado em 4 de dezembro de 2009)

\section{INTRODUÇÃo}

A uva é uma das frutas mais consumidas no mundo, tanto na forma in natura, quanto na forma de vinhos e sucos. No Brasil, a viticultura ocupa uma área de aproximadamente de 73.917 ha, com uma produção anual de 1.189.964 toneladas. Destacam-se com o principais estados produtores Pernambuco, Bahia, São Paulo, Minas Gerais, Rio Grande do Sul, Paraná e Santa Catarina, sendo que o maior volume de produção está concentrado no Rio Grande do Sul, representando 58,8\% da produção nacional (Agrianual, 2007).

As cultivares de Vitis vinifera, Merlot, Cabernet Sauvignon e Cabernet Franc, constituem-se em importantes uvas viníferas para a elaboração de vinhos tintos finos do Sul do Brasil. São consideradas uvas de alta qualidade, porém, em geral são bastante sensíveis às doenças fúngicas (Camargo et al., 2003).

Muitos são os fatores a serem manejados para se obter a máxima produtividade de um vinhedo. Um deles é o controle de doenças fúngicas, entre as quais se destaca a antracnose da videira, também denominada de varíola, olhode-passarinho ou negrão, causada por Elsinoe ampelina, com sintomas observados nas folhas, ramos e bagas (Sônego et al., 2005). Quando a severidade é alta, o vigor da planta é afetado, comprometendo não apenas a safra do ano como também as safras futuras (Amorim \& Kuniyuki, 2005).

1Universidade Estadual de Maringá/UEM - Departamento de Agronomia - Avenida Colombo - 5790 - Jardim Universitário - 87020 -090 - Maringá, PR alymaia2005@yahoo.com.br

2Universidade Estadual do Centro-Oeste/UNICENTRO - Guarapuava, PR

${ }^{3}$ Universidade Estadual do Centro-Oeste/UNICENTRO - Departamento de Agronomia - Guarapuava, PR 
Para a erradicação desse patógeno adotam-se medidas de controle, destacando-se o uso de agrotóxicos, o qual pode ocasionar a seleção de raças patogênicas, contaminação do meio ambiente, intoxicações e aumento do custo de produção (Alves Sobrinho et al, 2005). Dessa forma, é necessário buscar estratégias alternativas de controle de doenças, destacando-se a indução de resistência em plantas (Bonaldo et al., 2005) e a utilização de substâncias naturais bioativas com atividade antimicrobiana (Camili et al., 2007).

Dentre essas alternativas, a quitosana apresenta grande potencial. Essa substância é um polímero policatiônico $ß-1,4$ ligado à $\mathrm{D}$-glucosamina definido como um diacetilato de quitina, sendo um polissacarídeo natural extraído da casca ou exoesqueleto de crustáceos como camarão, caranguejo, lagosta e de plantas como as algas marinhas e da parede celular de alguns fungos (Khor, 2001). Oh et al. (1998) sugeriram que a quitosana tem um duplo efeito na interação patógeno-hospedeiro, ou seja, apresenta atividade antifúngica e pode induzir a ativação de defesa da planta, com a produção de enzimas. Bautista-Baños et al. (2003) verificaram, em testes in vitro, efeito fungicida da quitosana a 2 e $3 \%$ sobre o fungo Colletotrichum gloeosporioides, assim como o controle da antracnose em frutos de mamão, quando tratados com $1,5 \%$ de quitosana. Resultados positivos com o uso de quitosana também foram reportados para o controle de Botyitis cinerea em uvas (Ait Barka et al., 2004) e morangos (Bhaskara Reddy, 2000) e Puccinia arachidis em amendoim (Sathiyabama \& Balasubramanian, 1998).

Poucas são as pesquisas sobre o efeito da quitosana no desenvolvimento de plantas. No entanto, Ait Barka et al. (2004), com o objetivo de avaliar o potencial da quitosana no desenvolvimento vegetativo e in vitro de plântulas de videira, verificaram aumento no comprimento dos brotos e peso seco de raízes e brotos quando adicionaram $1,75 \%(\mathrm{v} / \mathrm{v})$ de chitogel, produto à base de quitosana, em meio de cultura.

Objetivou-se, neste trabalho, avaliar os efeitos da quitosana no desenvolvimento de plântulas cultivadas in vitro de videira (Vitis vinifera L. cv. Merlot) e no crescimento micelial in vitro, do fungo Elsinoe ampelina.

\section{MATERIAL E MÉTODOS}

Realizou-se, este trabalho, no Laboratório de Cultura de Tecido e de Fitopatologia, do Departamento de Agronomia da Universidade Estadual do Centro-Oeste (UNICENTRO), em Guarapuava-PR. Como fonte de quitosana foi utilizado o produto comercial Fish Fértil Indure ${ }^{\circledR}\left(20 \mathrm{~g} \mathrm{~L}^{-1}\right.$ de quitosana),
Fish Indústria e Comércio de Fertilizantes Ltda. (AgroBac Bio TecnologySolution), Mogi-Mirim-SP.

\section{Efeito da quitosana no desenvolvimento vegetativo de plântulas de videira cv. Merlot}

Neste experimento foram utilizados explantes já estabelecidos in vitro a partir de gemas apicais e laterais da videira cv. Merlot, retiradas de matrizes de área experimental do Departamento de Agronomia da UNICENTRO. Esses explantes consistiram de segmentos nodais com cerca de 1 $\mathrm{cm}$ de comprimento cada, possuindo uma gema axilar dormente, transferidos para meio de cultura DSD1 (Silva \& Doazan, 1995), acrescido das seguintes concentrações de quitosana: 0; 25; 50,100; 150 e $200 \mathrm{mg} \mathrm{L} \mathrm{m}^{-1}$. A cultura foi mantida em c âmara de crescimento com temperatura de $25^{\circ} \mathrm{C}$ e fotoperíodo de 16 horas de luz proveniente de lâmpadas fluorescentes, com uma intensidade de 2500 lux.

$\mathrm{O}$ delineamento experimental foi inteiramente casualizado, com seis tratamentos, seis repetições e a parcela experimental constituída por quatro explantes. Após 90 dias de cultivo in vitro, as plântulas foram avaliadas quanto ao número de raízes e de folhas, comprimento de raízes e de parte aérea, massa fresca da planta inteira e porcentagem de enraizamento e brotação.

\section{Efeito da quitosana sobre crescimento micelial in vitro do fungo Elsinoe ampelina}

Para este experimento foi realizado isolamento do patógeno a partir de bagas de uvas provenientes da região de Guarapuava-PR, o qual foi mantido como cultura pura de cultura BDA (Batata-dextrose-ágar), durante oito dias de incubação.

Para realização do experimento in vitro adicionouse ao meio BDA as concentração de 0, 60, 120, 180, 240 e $300 \mathrm{mg} \mathrm{L}^{-1}$ de quitosana. Em seguida, os meios foram autoclavados durante 20 minutos, a $120^{\circ} \mathrm{C}$ e pressão de 1 atm, e vertidos em placas de Petri de $70 \mathrm{~mm}$ de diâmetro, onde inoculou-se o fungo a partir de discos de $8 \mathrm{~mm}$ de diâmetro colocados no centro da placa. Tais placas foram incubadas em câmara de crescimento (B.O.D.) a $25 \pm 1^{\circ} \mathrm{C}$, no escuro. Aos 6 e 9 dias após incubação, avaliou-se o crescimento micelial, através da medida do diâmetro $(\mathrm{cm})$ da colônia, com auxílio de paquímetro digital. O delineamento experimental adotado foi inteiramente casualizado, com seis tratamentos, quatro repetições e parcela experimental constituída por uma placa de Petri.

Todos os resultados foram submetidos à análise de variância e de regressão polinomial, ao nível de 5\% probabilidade, utilizando-se o programa estatístico SISVAR (Ferreira, 2008). 


\section{RESULTADOS E DISCUSSÃO}

Efeito da quitosana no desenvolvimento in vitro de plântulas de videira cv. Merlot

Para as variáveis, comprimento médio da parte aérea, massa fresca da planta inteira, porcentagem de estacas enraizadas e porcentagem de estacas brotadas houve decréscimo linear em função das doses de quitosana (Figuras 1, 2, 3 e 4).

Em relação às variáveis, número de raízes, comprimento médio de raízes e número de folhas não houve diferenças significativas entre os tratamentos (Tabela 1). Ait Barka et al. (2004), avaliando o potencial da quitosana no desenvolvimento vegetativo de plântulas de videira cv. Chardonnay, verificaram que a adição de $1,75 \%(\mathrm{v} / \mathrm{v})$ de chitogel, produto à base de quitosana, em meio de cultura promoveu aumento no comprimento dos brotos e peso seco de raízes e brotos. No entanto, a concentração de $2 \%$ de chitogel, teve um efeito negativo no crescimento das plântulas e concentrações maiores promoveram morte das mesmas.

\section{Efeito da quitosana sobre o crescimento micelial in vitro do fungo Elsinoe ampelina}

Neste experimento, verificou-se redução do diâmetro da colônia do fungo Elsinoe ampelina com o aumento das concentrações de quitosana, com significância para regressão quadrática nos dois períodos

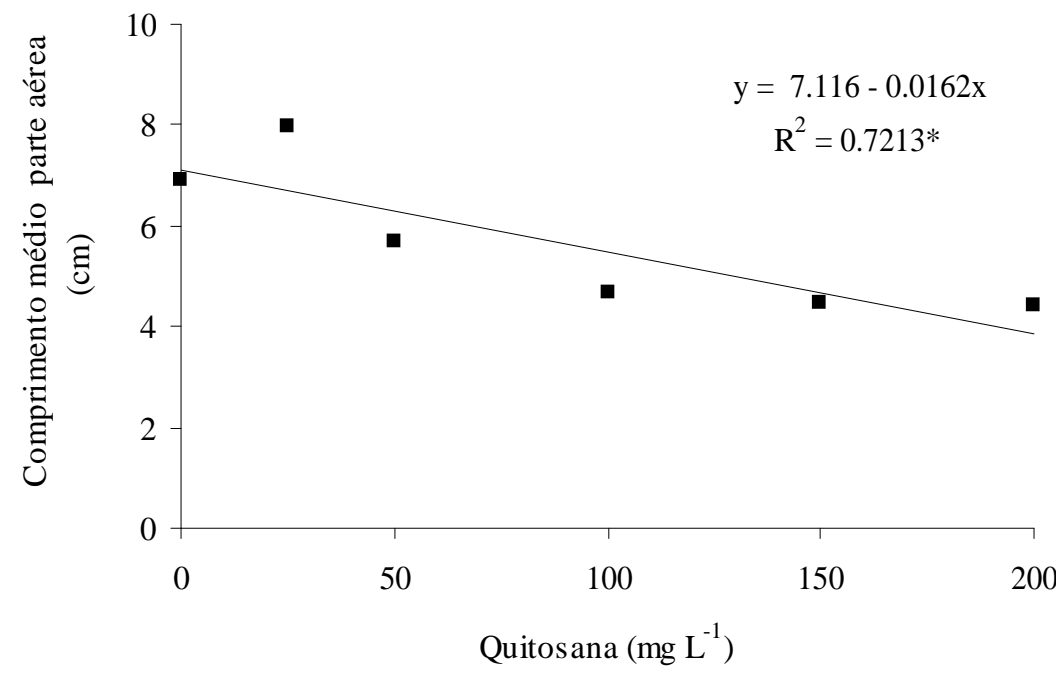

Figura 1 - Comprimento médio da parte aérea de plântulas de videira cv. Merlot, mantidas em meio de cultivo DSD1, acrescido com diferentes concentrações de quitosana (Guarapuava-PR, 2008).

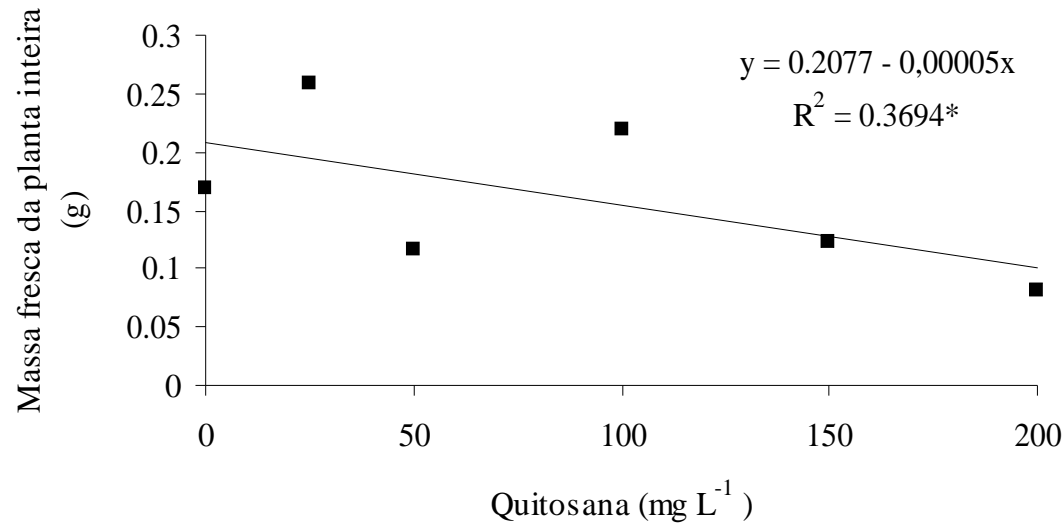

Figura 2 - Massa fresca de plântulas de videira cv. Merlot, mantidas em meio de cultivo DSD1, acrescido com diferentes concentrações de quitosana (Guarapuava-PR, 2008). 
de avaliação, aos 6 e 9 dias após incubação (Figura 5). Nota-se que, na concentração de $300 \mathrm{mg} \mathrm{L}^{-1}$ houve o máximo efeito fungistático, ou seja, redução de $81,7 \%$ sobre o desenvolvimento de E. ampelina. Tal efeito foi observado por El Ghaouth et al. (1992), quando pulverizaram morangos com quitosana, verificaram redução da infecção causada por Botrytis cinerea devido à indução da atividade da glucanohydrolase, melhorando a qualidade dos frutos.

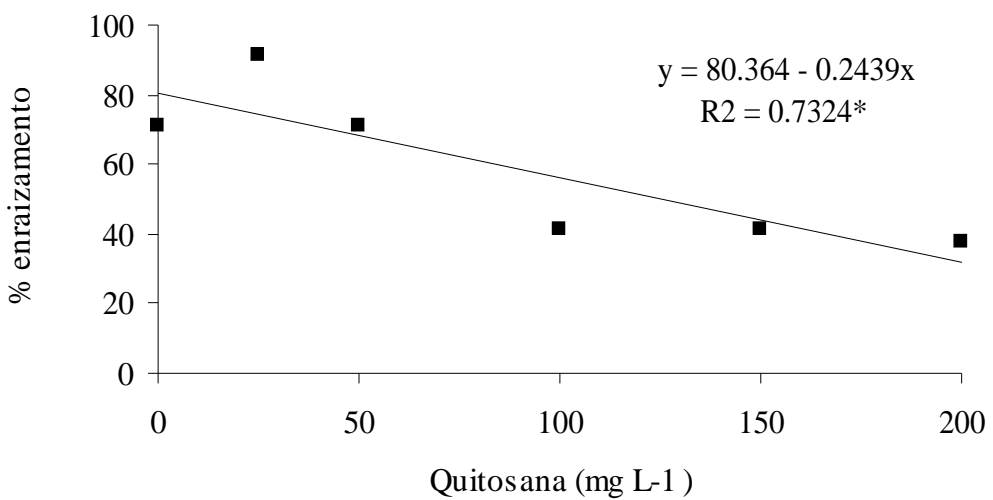

Figura 3 - Porcentagem de enraizamento de plântulas de videira cv. Merlot, mantidas em meio de cultivo DSD1, acrescido com diferentes concentrações de quitosana (Guarapuava-PR, 2008).

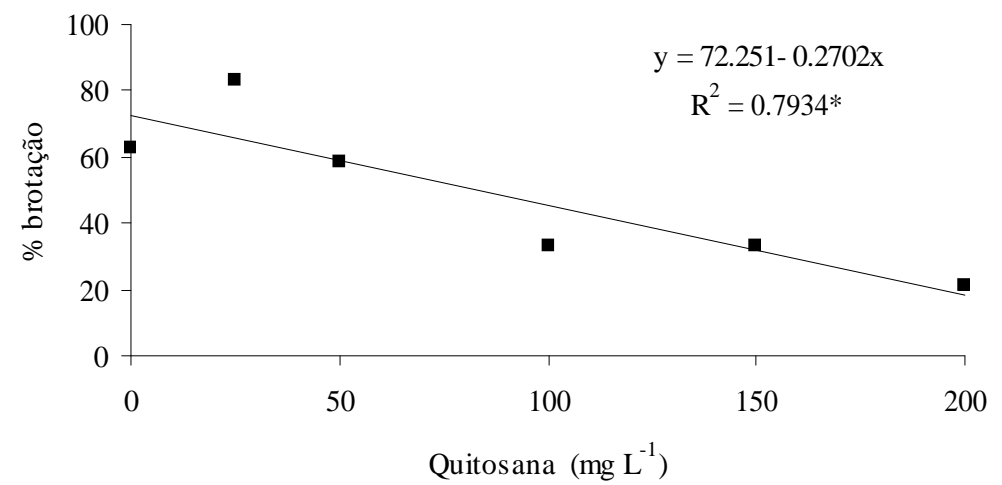

Figura 4 - Porcentagem de brotação de plântulas de videira cv. Merlot, mantidas em meio de cultivo DSD1, acrescido com diferentes concentrações de quitosana (Guarapuava-PR, 2008).

Tabela 1 - Numero e comprimento médio de raízes e número de folhas de plântulas de videira cv. Merlot, mantidas em meio de cultivo DSD1, acrescido das diferentes concentrações de quitosana (Guarapuava-PR, 2008).

\begin{tabular}{cccc}
\hline Tratamentos $\left(\mathrm{mg} \mathrm{L}^{-1}\right)$ & Número de raízes & Comprimento médio de raízes $(\mathrm{cm})$ & Número de folhas \\
\hline 0 & 1,98 & 2,48 & 7,8 \\
25 & 2,49 & 2,87 & 8,11 \\
50 & 2,16 & 1,89 & 6,94 \\
100 & 2,56 & 1,55 & 7,43 \\
150 & 3,29 & 1,99 & 7,62 \\
200 & 2,14 & 1,71 & 6,66 \\
CV \% & 45,6 & 48,96 & 22,63 \\
Pr>Fc & $0,388^{\mathrm{ns}}$ & $0,2433^{\mathrm{ns}}$ & $0,665^{\mathrm{ns}}$ \\
\hline
\end{tabular}

${ }^{\text {ns }}=$ não significativo.

Ciênc. agrotec., Lavras, v. 34, n. 6, p. 1425-1430, nov./dez., 2010 


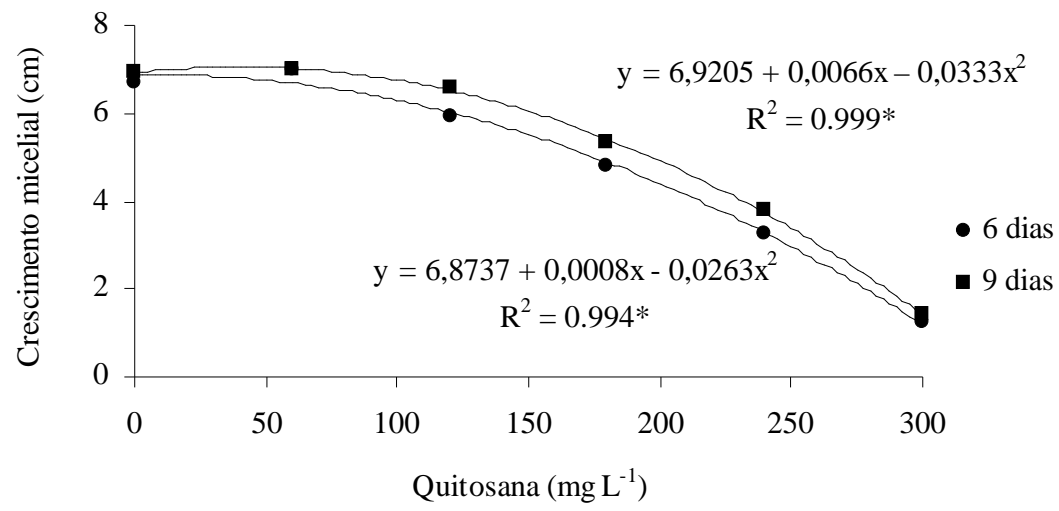

Figura 5 - Crescimento micelial $(\mathrm{cm})$ de Elsinoe ampelina em função de concentrações crescentes de quitosana, aos 6 e 9 dias após incubação em câmara de crescimento (Guarapuava-PR, 2008).

De acordo com Liu et al. (2007), a quitosana apresentou efeitos fungistático sobre o desenvolvimento de B. cinerea e Penicillium expansum, inibindo o crescimento micelial do primeiro fungo a partir da concentração de $0,5 \%$ do polissacarídeo e redução inversamente proporcional ao aumento da concentração para o segundo patógeno. Di Piero \& Garda (2008) verificaram que, além da inibição do crescimento micelial nas concentrações de 1 a $5 \mathrm{mg} \mathrm{mL}^{-1}$, a quitosana suprimiu a germinação de conídios de Colletotrichum lindemuthianum, agente causal da antracnose feijão.

Bhaskara Reddy et al. (1999) constataram que a quitosana protegeu tomate, pepino, ervilha, melão, morango e alface contra mofos pulverulentos e outras doenças. De forma semelhante, Ben-Shalom et al. (2003) verificaram que a quitosana tem o potencial de controlar o mofo cinzento, causado por $B$. cinerea em plantas de pepino.

De acordo com os resultados deste trabalho, a quitosana possui efeito fungistático sobre o fungo $E$. ampelina, demonstrando potencial de utilização no controle da antracnose da videira em sistema de produção orgânica de uvas. A quitosana apresentou efeito fitotóxico em plântulas de videira cv. Merlot, no entanto, material desenvolvido in vitro normalmente é muito mais sensível do que plantas de videiras em situação de campo. Com isso, faz-se necessária a realização de pesquisa em condições de cultivo, para, futuramente, determinar recomendações adequadas e seguras ao meio ambiente para a aplicação em vinhedos, sem causar fitotoxidez ou até mesmo funcionando como um promotor de crescimento.

\section{CONCLUSÕES}

A quitosana apresentou efeito fitotóxico em plântulas de videira cv. Merlot, reduzindo a porcentagem de brotação e enraizamento, o comprimento médio da parte aérea e a massa fresca da planta toda.

A quitosana apresentou efeito fungistático sobre o fungo Elsinoe ampelina, reduzindo o diâmetro micelial em $81,7 \%$ na concentração de $300 \mathrm{mg} \mathrm{L}^{-1}$.

\section{REFERÊNCIAS BIBLIOGRÁFICAS}

AGRIANUAL. Anuário da Agricultura Brasileira. São Paulo: BASF-The chemical Company, 2007. 516p.

AIT BARKA, E.; EULLAFFROY, P.; CLÉMENT, C.; VERNET, V. Chitosan improves development, and protects Vitis vinifera L. against Botrytis cinerea. Plant Cell Reports, Heidbelberg, v.22, n.8, p.608-614, Mar. 2004.

ALVES SOBRINHO, C.A.; FERREIRA, P. de T. de O.; CAVALCANTI, L.S. Indução abióticos. In:

Indução de resistência em plantas a patógenos e insetos. Piracicaba: FEALQ, 2005.

AMORIM, L.; KUNIYUKI, H. Doenças da videira. In: KIMATI, H.; AMORIM, L.; REZENDE, J.A.M.; BERGAMIN FILHO, A.; CAMARGO, L.E.A. (Ed.). Manual de fitopatologia: doenças das plantas cultivadas. 4.ed. São Paulo: [s.n.], 2005. v.2, p.639651 .

BAUTISTA-BAÑOS, S.; HERNÁNDEZ-LÓPEZ, M.; BOSQUEZ-MOLINA, E.; WILSON, C.L. Effects of chitosan and extracts on growth of Colletotrichum gloeosporioides, anthracnose levels and quality of papaya fruit. Crop Protection, London, v.22, n.9, p.10871092, Nov. 2003. 
BEN-SHALOM, N.; ARDI, R.; PINTO, R.; AKI, C.; FALLIK, E. Controlling graymold caused by Botrytis cinerea in cucumber plants bymeans of chitosan. Crop Protection, London, v.22, n.2, p.285-290, Mar. 2003.

BHASKARA REDDY, M.V.; ARUL, J.; ANGERS, P.; COUTURE, L. Chitosan treatment of wheat seeds induces resistance to Fusarium graminearum and improves seed Quality. Journal of Agricultural and Food Chemistry, Washington, v.47, n.3, p.1208-1216, Mar. 1999.

BHASKARA REDDY, M.V.; BELKACEMI, K.; CORCUFF, R.; CASTAIGNE, F.; ARUL, J. Effect of preharvest chitosan sprays on pos-harvest infection by Botritis cinerea and quality of strawberry fruit.

Postharvest Biology and Technology, Amsterdam, v.20, n.1, p.39-51, Aug. 2000.

BONALDO, S.M.; PASCHOLATI, S.F.; ROMEIRO, R.S. Indução de resistência: noções básicas e perspectivas. In: _. Indução de resistência em plantas a patógenos e insetos. Piracicaba: FEALQ, 2005.

CAMARGO, A.U. Porta-enxertos e cultivares. In: PROTAS, J.S.F. Uvas viníferas para processamento em clima temperado. Brasília: Embrapa Uva e Vinho, 2003. Disponível em: 〈http://sistemasdeproducao.cnptia. embrapa.br/FontesHTML/Uva/UvasViniferasRegioes ClimaTemperado/> . Acesso em: 19 set. 2007.

CAMILI, E.C.; BENATO, E.A.; PASCHOLATI, S.F.; CIA, P. Avaliação de quitosana, aplicada em pós-colheita, na proteção de uva 'Itália' contra Botrytis cinerea. Summa Phytopathologica, Botucatu, v.33, p.215-221, July/Sept. 2007.

DI PIERO, R.M.; GARDA, M.V. Quitosana reduz a severidade da antracnose e aumenta a atividade de glucanase em feijoeiro-comum. Pesquisa Agropecuária Brasileira, Brasília, v.43, n.9, p.1121-1128, set. 2008.

EL-GHAOUTH, E.A.; ARUL, J.; GRENIER, J.; ASSELIN, A. Antifungal activity of chitosan on two postharvest pathogens of strawberry fruits. Phytopathology, Saint Paul, v.82, n.4, p.398-402, 1992.

FERREIRA, D.F. SISVAR: um programa para análises e ensino de estatística. Revista Cientifíca Symposium, Lavras, v.6, n.2, p.36-41, jul./dez. 2008.

KHOR, E. Chitin: fulfilling a biomaterials promise. Oxford: Elsevier Science, 2001.

LIU, L.; TIAN, S.; MENG, X.G.; XU, Y. Effects of chitosan on control of postharvest diseases and physiological responses of tomato fruits. Postharvest Biology and Tecnology, Amsterdam, v.44, p.300-306, June 2007.

OH, S.K.; CHO, D.; YU, S.H. Development of integrated pest management techniques using biomass for organic farming: I., suppression of late blight and fusarium wilt of tomato by chitosan involving both antifungal and plant activating activities. Korean Society of Plant Pathology, Suwon, v.14, p.278-285, 1998.

SATHIYABAMA, M.; BALASUBRAMANIAM, R. Chitosan induces resistance components in Arachis hipogaea against leaf rust caused by Puccinia arachidis Speg. Crop Protection, London, v.17, n.4, p.307-313, June 1998.

SILVA, A.L. da; DOAZAN, J.P. Une méthode d'irradiation aux rayons gamma appliquée à des porte-greffes de vigne in vitro. Journal International des Sciences de la Vigne et du Vin, Bordeaux, v.29, p.1-9, 1995. 